\title{
Perceptions of Portuguese psychologists about behavioural inhibition/social withdrawal and their related intervention needs during early childhood
}

\author{
Maryse Guedes ${ }^{1}$, Leandra Coelho ${ }^{1}$, António J. Santos ${ }^{1}$ \& Manuela Veríssimo ${ }^{1}$ \\ ${ }^{1}$ William James Center for Research, ISPA - Instituto Universitário
}

\begin{abstract}
Given the high prevalence of anxiety disorders, there has been an increasing need to intervene on the early risk factors for their development, namely behavioral inhibition and social withdrawal (BI/SW) during early childhood. However, the participation rates in preventive evidence-based interventions targeted at BI/SW have been modest, due to the gaps in parents' and key gatekeepers' (teachers and pediatricians) problem recognition. Given their pivotal role in enhancing problem recognition, this study aimed to explore the perceptions of Portuguese psychologists about BI/SW and their related intervention needs. Eighteen psychologists were distributed into three focus groups. Each focus group was moderated by a trained researcher, using a semi-structured interview guide. The thematic analysis revealed that Portuguese psychologists identified the manifestations and consequences of BI/SW, particularly in the social domain. Portuguese psychologists recommended the development of multi-component family interventions and interventions targeted at preschool teachers to promote social skills in the classroom.
\end{abstract}

Keywords: Behavioral inhibition; social withdrawal; preschool years; evidence-based preventive interventions.

\begin{abstract}
Perceções dos psicólogos portugueses acerca da inibição comportamental/ retraimento social e das necessidades de intervenção que lhes subjazem durante a infância precoce: Dada a elevada prevalência das perturbações de ansiedade, verificou-se uma necessidade emergente de intervir nos fatores de risco precoce para o seu desenvolvimento, nomeadamente na inibição comportamental e no retraimento social (IC/RS) em idade pré-escolar. Porém, a participação em intervenções preventivas para a IC/RS é modesta, devido ao reduzido reconhecimento do problema pelos pais e profissionais (educadores e pediatras) que trabalham com o público-alvo. Dado o seu papel central na promoção do reconhecimento do problema, este estudo teve como objetivo explorar as perceções dos psicólogos portugueses acerca da IC/RS e das necessidades de intervenção que lhes subjazem. Dezoito psicólogos foram distribuídos em três grupos focais. Cada grupo foi moderado por um investigador, seguindo um guião semiestruturado. Os participantes identificaram as manifestações e consequências da IC/RS (particularmente no domínio social) e recomendaram o desenvolvimento de intervenções familiares multimodais e de intervenções para educadores, destinadas à promoção de competências sociais no jardim-de-infância.
\end{abstract}

Palavras-chave: Inibição comportamental; retraimento social; idade pré-escolar; intervenções preventivas baseadas na evidência.

Anxiety disorders are the most prevalent mental health disorders in Europe and have significant costs for individuals, families and healthcare systems (Bandelow \& Michaelis, 2015). Intervening in the early risk factors of anxiety disorders, such as high and stable behavioral inhibition and social withdrawal (BI/SW) during early childhood (Chronis-Tuscano et al., 2009), can have a significant impact in reducing these costs (Chronis-Tuscano, Danko, Rubin, Coplan, \& Novick, 2018). In fact, the preschool years are the most optimal period for intervening, due to early neuroplasticity (Hirschfeld-Becker \& Biederman, 2002).

\section{Behavioral inhibition/social withdrawal and their consequences}

Within a developmental and transactional framework (Rubin, Coplan, \& Bowker, 2009), BI can be understood as a biologically-based predisposition to experience fear and wariness during the exposure to

${ }^{1}$ Correspondence address: Rua Jardim do Tabaco no 34, 1149-041 Lisboa, Portugal. E-mail: mguedes@ispa.pt. This study is part of the research project "Adaptation and preliminary evaluation of the Turtle Program in Portugal", conducted by the R\&D William James Center for Research, ISPA - Instituto Universitário and funded by the Calouste Gulbenkian Foundation (process no 222926). Maryse Guedes, is supported by a scholarship from the Portuguese Foundation for Science and Technology (SFRH/BPD/114846/2016). 
novel persons, situations and activities (Fox, Henderson, Marshall, Nichols, \& Ghera, 2005). When high and stable during early childhood, BI is posited to be an antecedent of SW (Fox, Henderson, Rubin, Calkins \& Schmidt, 2001), which refers to a self-imposed isolation in the presence of unfamiliar and familiar peers at preschool, due to internalized feelings of social anxiety (Rubin, Bowker, Barstead, \& Coplan, 2018; Rubin et al., 2009).

Based on the extant classical theoretical work that provide support for the idea that children's peer interactions during early childhood serve to promote adaptive emotional, social, and social-cognitive functioning (see Rubin, Bowker et al., 2018, for a review), Rubin's developmental and transactional model (Rubin et al., 2009) establishes that high and stable BI/SW may be associated with a variety of negative socioemotional consequences from early childhood to adolescence.

Research has shown that highly inhibited young children typically avoid unfamiliar social and nonsocial stimuli and, when confronted with these stimuli, cease their play behaviors, withdraw to the proximity of caregivers, remain vigilant and display specific patterns of emotional reactivity and dysregulation, characterized by low thresholds for the evocation of negative affect and difficulty to be calmed once emotionally upset (Kagan, Reiznik, \& Snidman, 1987; Rubin, Coplan, Fox, \& Calkins, 1995). According to a developmental and transactional approach (Rubin et al., 2009), parents often accommodate inhibited children's anxiety and respond to their behaviors in an overprotective way (Hane, Cheah, Rubin \& Fox, 2008; Lewis-Morrarty et al., 2012), speaking/acting for children in distressing situations instead of encouraging them to engage in developmentally important activities and of fostering their independence and emotion-regulation skills (Chronis-Tuscano et al., 2018). Given that emotionregulation skills are associated with socially competent behaviors, inhibited children who grow up in such family environments may continue to display intense distress, anxious and avoidant behaviors when exposed to social novelty and, ultimately, refrain from engaging in appropriate peer interactions during the preschool years (Rubin, Cheah \& Fox, 2001; Smith, Hastings, Henderson \& Rubin, 2019). When withdrawing from the peer group, socially wary preschoolers loose important developmental opportunities to learn about their social environments and how to behave within them, to acquire interpersonal negotiation and perspective-taking skills, and to develop an enhanced understanding of others' emotions and of the self in relation to others (Rubin, Bowker et al., 2018). Beyond withdrawing from the peer group, socially wary children also participate less on preschool activities and speak less during conversations, so that they often perform less well on tests of certain language abilities than their non-inhibited peers (Coplan \& Weeks, 2009; Spere, Schmidt, Theall, \& Martin-Chang, 2004; Strand, Pula, Parks, \& Cerna, 2011). This have been found to have negative implications for withdrawn children's emergent literacy (i.e., pre-reading and mathematics; Spere \& Evans, 2009; Dobbs, Doctoroff, Fisher, \& Arnold, 2006).

Due to low emotional, social and socio-cognitive skills, the developmental and transactional model (Rubin et al., 2009) establishes that children who continue to display socially wary behaviors over time are more likely to experience later peer exclusion and victimization (Correia, Santos, Freitas, Ribeiro, \& Rubin, 2014; Rubin, Barstead, Smith, \& Bowker, 2018) and to display poorer teacher-rated academic performance skills than their peers, due to their lower academic engagement in the classroom (Kalutskaya, Archbell, Rudasill, \& Coplan, 2015). Furthermore, the recognition of low emotional, social and socio-cognitive skills over time may lead withdrawn children to internalize negative self-cognitions, increasing their vulnerability for the development of later social anxiety and depression (Rubin, Bowker et al., 2018).

\section{Evidence-based interventions targeted at BI/SW during early childhood}

Due to these negative transactional influences (Rubin et al., 2009), there has been an increasing interest in evidence-based preventive interventions targeted at BI/SW during early childhood (Chronis-Tuscano et al., 2018). The few available interventions have focused primarily on the modification of overprotective and anxiogenic parenting behaviors. In fact, Rubin's developmental and transactional model (2009) establish that these parenting behaviors limit the development of children's independence and ageappropriate emotion-regulation, social and socio-cognitive skills and, ultimately, contribute to the maintenance of high BI/AW over time, increasing the risk of developing later negative socioemotional outcomes (Hane et al., 2008; Lewis-Morrarty et al., 2012). In Australia, Rapee and Jacobs (2002) have developed the Cool Little Kids, a six-weeks parent-only intervention, during which trained psychologists provide psychoeducation about the nature and development of anxiety, parent-management techniques to deal with anxiogenic parenting behaviors, gradual exposure and cognitive restructuring of parents' own worries. More recently, Chronis-Tuscano and colleagues (2015) have developed the Turtle Program in the USA. Contrary to the Cool Little Kids, the Turtle Program includes not only a parent component based on the principles of Parent-Child Interaction Therapy (Eyberg, Nelson, \& Boggs, 2008) adapted to 
anxiety problems (Pincus, Eyberg, \& Choate, 2005), but also a child component aimed at teaching and practicing social and emotion-regulation skills (Danko, O'Brien, Rubin, \& Chronis-Tuscano, 2018). The parent and the child components are conducted by two trained psychologists each. The parent component of the Turtle Program combines the benefits of parent psychoeducation with those of in-vivo therapist coaching (Chronis-Tuscano et al., 2015) with the purpose of teaching and coaching parents to: (1) follow the child's lead during play activities and positively reinforce child's social-approach and independent behaviors (Child-Directed Interaction); (2) apply these skills in anxious social situations, thus providing opportunities for exposure and facilitated coping (Bravery-Directed Interaction); and (3) discriminate between anxious and oppositional behaviors, implementing discipline strategies for the latter ones (Parent-Directed Interaction; Danko et al., 2018). The child component of the Turtle Program extends the principles of Social-Skills Facilitated Play Program (Coplan, Schneider, Matteson, \& Graham, 2010) and promotes the practicing of child's skills in a peer group context, using techniques that have been described as components of effective child interventions, such as social skills training, systematic modelling of relevant social skills, as well as training in social problem-solving, emotion-regulation strategies, and relaxation (Danko et al., 2018).

Despite their benefits for child socioemotional outcomes (Chronis-Tuscano et al., 2015; Rapee, Kennedy, Ingram, Edwards, \& Sweeney, 2005), parent participation in preventive evidence-based interventions targeted at BI/SW has been typically modest (Bayer et al., 2017). Theoretical models of help-seeking establish that parental appraisals of child mental health problems are the central forces behind the decision to seek help (Cauce et al., 2002; Godoy \& Carter, 2013; Srebnik, Cauce, \& Baydar, 1996). Research has found that parents of young children are less likely to recognize anxiety-related problems as problematic than externalizing ones and often believe that anxiety will disappear spontaneously with age (Carpenter, Pincus, Perrin, Bair-Merrit, \& Mian, 2018; Mian, 2014; Reardon, Harvey, Young, O'Brien, \& Creswell, 2018). Thus, parents of young children are typically less prone to engage in the subsequent steps of the help-seeking process for anxiety-related problems (Mian, 2014), that is, to decide to seek help, identify an action plan, and take action (Godoy \& Carter, 2013).

According to the theoretical models of help-seeking (Cauce, 2002; Srebnik et al., 1996), many contextual factors can enhance or reduce parental problem recognition and engagement in each step of the help-seeking process. The appraisals of professionals about the problem (Godoy \& Carter, 2013; Srebnik et al., 1996) and its intervention needs may have a significant influence. In fact, professionals who establish regular and proximal relationships with parents of young children in the community, like school staff and primary care pediatricians, can act as key gatekeepers for enhancing problem recognition and referral (Carpenter et al., 2018).

\section{Perceptions of professionals about BI/SW and its intervention needs}

Extant research has found that teachers usually reported concerns toward inhibited/withdrawn behaviors and acknowledged their negative consequences for peer relationships, language and academic development (Coplan, Bullock, Archbell, \& Bosacki, 2015; Coplan, Hughes, Bosacki, \& Rose-Krasnor, 2011). However, a significant proportion of teachers endorsed more frequently indirect strategies (i.e., seeking additional information or monitoring the situation) with inhibited/withdrawn children than with exuberant and aggressive children (Coplan et al., 2011); this suggest that teachers continue to be quite unsure of how to respond to inhibited/withdrawn behaviors and may be less prone to intervene, because these behaviors are typically not disruptive to classroom functioning (Coplan et al., 2011; Bosaki, Coplan, Rose-Krasnor, \& Hughes, 2011; Coplan \& Arbeau, 2008). Similar gaps have been also identified in the perceptions of primary care paediatricians. More specifically, studies have shown that primary care paediatricians were not always fully aware of the severity and long-term consequences associated with children's anxiety-related problems (Godoy \& Carter, 2013; O’Brien, Harvey, Young, Reardon, \& Creswell, 2017). Even when they are aware of these issues, primary care paediatricians typically did not receive an adequate level of training in the identification of the early risk factors of anxiety-related problems and their effective referral (Carpenter et al., 2018).

Thus, psychologists may be important informants for teachers and primary care paediatricians and may prepare them to identify young children who are at increased risk of developing anxiety-related problems, refer families to appropriate evidence-based interventions and, ultimately, enhance parental problem recognition and early mental health help-seeking (Carpenter et al., 2018). To the best of our knowledge, the perceptions of psychologists about BI/SW and their intervention needs remain relatively unexplored. Understanding these perceptions is especially important in cultural contexts, where evidence-based preventive interventions targeted at $\mathrm{BI} / \mathrm{SW}$ are not yet available. This is the case of Portugal, which has one of the highest percentages (16.5\%) of anxiety disorders in Europe (CaldasAlmeida \& Xavier, 2013). 


\section{Culture and perceptions about $\mathrm{BI} / \mathrm{SW}$ and its related intervention needs}

According to an ecological approach (Bronfenbrenner \& Morris, 2006), cultural norms and values shape the beliefs, emotions and behavioral reactions toward social behaviors, such as BI/SW (Rubin et al., 2006). In Southern European countries, traditional family-oriented values (Wall \& Gouveia, 2014) coexist with an emphasis on sociability and emotional expressiveness (Casiglia, LoCoco, \& Zappulla, 1998). The balance between collectivist and individualistic values (Wall \& Gouveia, 2014) may influence how Portuguese psychologists perceive BI/SW, their consequences and their related intervention needs, in a specific way.

Due to the existing limitations in the current state-of-art knowledge, qualitative methods can be useful in gaining an in-depth understanding of psychologists' views. In particular, focus groups have been recognized as a useful method for exploring attitudes and guiding intervention development (Krueger \& Casey, 2014). Thus, the purpose of the present study was to describe the perceptions of Portuguese psychologists about BI/SW, their consequences and intervention needs.

\section{METHOD}

\section{Participants}

A total of 18 Portuguese psychologists participated in this study. Participants were selected based on the following criteria: (1) being specialized in Clinical or Developmental Psychology; (2) having experience in working with young children and/or their parents; and (3) being able to speak and understand Portuguese.

Table 1 shows that most participants were females and were specialized in Clinical Psychology. Half of the participants held a PhD, whereas the other half held a MsC. Participants were distributed into three groups, composed by six participants according to their availability to attend the discussion. The length of professional experience was taken into account in group composition, to minimize the possibility that less experienced participants felt intimidated of exposing their perspectives in front of more experienced participants. The number of participants who worked in the same organization in each group was controlled to minimize the interference of familiarity between participants and to ensure the heterogeneity of each group.

Table 1. Sociodemographic characteristics of the total sample and of each focus group.

\begin{tabular}{|c|c|c|c|c|}
\hline & Total sample $(\mathrm{N}=18)$ & FG1 $(n=6)$ & FG2 $(n=6)$ & FG3 $(n=6)$ \\
\hline & $M(S D) / n(\%)$ & $M(S D) / n(\%)$ & $M(S D) / n(\%)$ & $M(S D) / n(\%)$ \\
\hline Age & $34.11(4.71)$ & $37.50(5.05)$ & $31.67(1.97)$ & $33.17(4.19)$ \\
\hline Length of professional experience & $10.11(5.06)$ & $13.83(4.62)$ & $6.83(0.87)$ & $10.17(4.62)$ \\
\hline \multicolumn{5}{|l|}{ Gender } \\
\hline Female & $16(89 \%)$ & $5(83 \%)$ & $6(100 \%)$ & $5(83 \%)$ \\
\hline Male & $2(11 \%)$ & $1(17 \%)$ & $0(0 \%)$ & $1(17 \%)$ \\
\hline \multicolumn{5}{|l|}{ Marital status } \\
\hline Married/cohabitating & $10(56 \%)$ & $4(67 \%)$ & $4(67 \%)$ & $2(33 \%)$ \\
\hline Single & $8(44 \%)$ & $2(33 \%)$ & $2(33 \%)$ & $4(67 \%)$ \\
\hline Had children & $7(39 \%)$ & $4(67 \%)$ & $2(33 \%)$ & $1(17 \%)$ \\
\hline \multicolumn{5}{|l|}{ Academic degree } \\
\hline $\mathrm{PhD}$ & $9(50 \%)$ & $4(67 \%)$ & $2(33 \%)$ & $3(50 \%)$ \\
\hline $\mathrm{MsC}$ & $9(50 \%)$ & $2(33 \%)$ & $4(67 \%)$ & $3(50 \%)$ \\
\hline \multicolumn{5}{|l|}{ Specialization } \\
\hline Clinical Psychology & $14(78 \%)$ & $6(100 \%)$ & $2(33 \%)$ & 5 (83\%) \\
\hline Developmental Psychology & $4(22 \%)$ & $0(0 \%)$ & $4(67 \%)$ & $1(17 \%)$ \\
\hline
\end{tabular}

Note. FG refers to Focus Group.

\section{Instruments}

Sociodemographic questionnaire. This questionnaire collected information about the sociodemographic characteristics of the participants. 
Semi-structured interview guide. This semi-structured interview guide was fully described elsewhere (Guedes et al., 2019) and was developed by the research group, in accordance with the recommendations of Krueger and Casey (2014). The present study only focused on the two introductory questions and on the transition question of the semi-structured interview guide. After a brief introduction to the focus group objectives and procedures, participants were asked to introduce themselves. Then, participants were asked to explain how they understood BI/SW during early childhood and to describe the consequences that they anticipated that BI/SW could have for the child and his/her family. Then, participants were asked to reflect on the kind of interventions that may be useful for inhibited/withdrawn preschoolers. At the end of the discussion, participants were given the opportunity to make additional comments.

\section{Procedures}

This study was approved by the ISPA Ethics Committee. Data were collected, using a focus groups methodology. Twenty-eight psychologists from the contact networks of the research group who met the inclusion criteria were initially invited to participate. Three psychologists (11\%) declined the invitation. Psychologists who agreed to participate were asked to sign a written informed consent and to complete the sociodemographic form. The focus groups were scheduled, according to the availability of the participants. After scheduling the focus groups, seven participants (25\%) withdrew. Each focus group lasted approximately two hours and was conducted by a trained moderator, in a quiet and comfortable location. After reviewing focus group objectives and procedures, the moderator ensured that all the participants agreed to allow the group discussion to be audio recorded. Then, the moderator conducted the discussion, using the semi-structured interview guide.

\section{Data analysis}

Data were analyzed based on a continuous process of data collection, reduction, display and verification (Huberman \& Miles, 1994), using QSR NVivo Pro 11. Each group discussion was transcribed verbatim, using fictional names. Following an existentialist/realistic epistemological approach, a deductive thematic analysis was conducted to identify, analyze and report patterns (themes) within data (Braun \& Clarke, 2006). Themes were meaningful units (references), defined as set of phrases about the same topic. Data were initially coded and collated for each code; thereafter, codes were collated into themes and subthemes, which, in turn, were reviewed and analyzed. According to the recommendations of Krueger and Casey (2014), frequency, extensiveness, intensity, specificity, internal consistency and perceived importance were reported. Two independent raters analyzed the data to calculate average inter-rater agreement percentages and Cohen's Kappa coefficients for each theme and sub-theme. Cohen's Kappa coefficients were interpreted as: poor agreement (below 0.40 ), fair to good agreement ( 0.40 to 0.75 ), and excellent agreement (over 0.75). After data analysis, each participant was given information about the final themes and was able to individually comment whether these themes adequately reflected their perspectives.

\section{RESULTS}

Table 2 presents the themes and sub-themes that were identified.

\section{BI/SW during early childhood}

All groups acknowledged that inhibited preschoolers usually display anxiety when exposed to social interactions with unfamiliar peers and adults and, gradually, with peers at preschool. More specifically, participants explained that inhibited children usually avoid eye contact, refrain from initiating conversations with others, withdraw from the peer group and play alone, display freezing reactions or attention-seeking behaviors (e.g., tantrums, crying) when they are asked to interact with others.

Twenty-two percent of the participants from the sample mentioned that inhibited preschoolers often display anxiety when exposed to novel situations and activities that can result in a difficulty to engage in exploration behaviors and/or to separate from parents.

\section{Perceptions about the consequences of high BI during early childhood}

Consequences for child's socioemotional adjustment. Participants from the second (FG2) and the third (FG3) focus groups mentioned more frequently that high BI/SW may be associated with impaired social skills that can result in difficulties to establish and maintain age-appropriate social relationships and, ultimately, in peer exclusion and victimization. 
Table 2. Frequency and extension of the themes and sub-themes related to the understanding and consequences of BI/SW and their related intervention needs.

\begin{tabular}{|c|c|c|c|c|c|c|c|c|c|c|}
\hline \multirow[b]{2}{*}{ Themes and sub-themes } & \multicolumn{2}{|c|}{ FG1 } & \multicolumn{2}{|c|}{ FG2 } & \multicolumn{2}{|c|}{ FG3 } & \multicolumn{2}{|c|}{ Total } & \multicolumn{2}{|c|}{ Average } \\
\hline & Ref. & Part. & Ref. & Part. & Ref. & Part. & Ref. & Part & $\%$ agr. & Kappas \\
\hline BI/SW & 6 & 5 & 6 & 5 & 7 & 6 & 19 & 16 & 99.90 & 0.95 \\
\hline Anxiety when exposed to social interactions & 4 & 4 & 5 & 5 & 6 & 4 & 15 & 13 & 99.93 & 0.95 \\
\hline $\begin{array}{l}\text { Anxiety when exposed to novel situations } \\
\text { and activities }\end{array}$ & 2 & 2 & 1 & 1 & 1 & 1 & 4 & 4 & 99.89 & 0.77 \\
\hline Consequences of $\mathrm{BI} / \mathrm{SW}$ & 16 & 6 & 27 & 5 & 14 & 5 & 57 & 16 & 99.58 & 0.93 \\
\hline Consequences for the child & 11 & 6 & 9 & 4 & 7 & 4 & 27 & 14 & 99.32 & 0.77 \\
\hline Impaired social skills & 2 & 1 & 4 & 3 & 5 & 3 & 11 & 7 & 99.79 & 0.52 \\
\hline $\begin{array}{l}\text { Limited autonomy and learning } \\
\text { opportunities }\end{array}$ & 6 & 5 & 1 & 1 & 2 & 2 & 9 & 8 & 99.96 & 0.96 \\
\hline Impaired emotional skills & 2 & 2 & 3 & 3 & 0 & 0 & 6 & 5 & 99.76 & 0.46 \\
\hline Negative self-cognitions & 1 & 1 & 1 & 1 & 0 & 0 & 2 & 2 & 100 & 0.99 \\
\hline Consequences for the family & 5 & 2 & 17 & 5 & 7 & 5 & 29 & 12 & 99.58 & 0.92 \\
\hline $\begin{array}{l}\text { Parental excessive worry and } \\
\text { overprotection }\end{array}$ & 4 & 2 & 5 & 4 & 3 & 2 & 12 & 8 & 99.74 & 0.74 \\
\hline $\begin{array}{l}\text { Parental normalization and } \\
\text { misunderstanding }\end{array}$ & 1 & 1 & 12 & 5 & 2 & 2 & 15 & 8 & 99.70 & 0.92 \\
\hline Stress in the couple relationship & 0 & 0 & 0 & 0 & 1 & 1 & 1 & 1 & 100 & 1 \\
\hline $\begin{array}{l}\text { Interaction problems with other family } \\
\text { members }\end{array}$ & 0 & 0 & 1 & 1 & 1 & 1 & 2 & 2 & 99.85 & 0.64 \\
\hline Intervention needs related to $\mathrm{BI} / \mathrm{SW}$ & 18 & 5 & 35 & 5 & 11 & 5 & 64 & 15 & 99.59 & 0.97 \\
\hline Psychoeducation about BI/SW & 5 & 4 & 3 & 2 & 2 & 2 & 10 & 8 & 99.89 & 0.95 \\
\hline Supervision of preschool teachers & 0 & 0 & 9 & 3 & 3 & 2 & 12 & 5 & 99.93 & 0.97 \\
\hline Promotion of emotion-regulation skills & 5 & 3 & 6 & 2 & 0 & 0 & 11 & 5 & 99.67 & 0.98 \\
\hline Gradual exposure and reinforcement & 8 & 3 & 0 & 0 & 2 & 2 & 10 & 5 & 99.98 & 0.98 \\
\hline Modification of parent-child interactions & 0 & 0 & 8 & 3 & 1 & 1 & 9 & 4 & 99.98 & 0.99 \\
\hline Modification of dysfunctional beliefs & 0 & 0 & 3 & 1 & 1 & 1 & 4 & 2 & 99.72 & 0.75 \\
\hline Promotion of parenting skills & 0 & 0 & 4 & 3 & 0 & 0 & 4 & 3 & 99.95 & 0.90 \\
\hline Couple-focused interventions & 0 & 0 & 2 & 1 & 2 & 2 & 4 & 3 & 99.97 & 0.92 \\
\hline
\end{tabular}

Note. FG refers to Focus Group. Ref. refers to the $\mathrm{n}^{\mathrm{0}}$ of references. Part. refers to the $\mathrm{n}^{\mathrm{0}}$ of participants. \% agr. refers to percentage of agreement.

Participants from the first focus group (FG1) mentioned more frequently that high BI/SW can be associated with limited autonomy and learning experiences. According to them, inhibited preschoolers usually become dependent from parents and experience difficulties to explore, adapt and respond flexibly to novel situations, to enjoy the learning experiences at preschool (especially, when these experiences are related to performance in front of others) and, ultimately, to develop age-appropriate linguistic and academic skills. Tina explained that these difficulties may have long-term consequences at school:

\section{"Highly inhibited children are more invisible for teachers, at school. Thus, if highly inhibited children} experience learning difficulties, teachers may not be able to identify them early."

Twenty-eight percent of the participants from the sample mentioned that high BI/SW may be associated with impaired emotional skills, such as emotional expressiveness, emotional regulation (especially, for anxiety) and help-seeking skills to manage emotional over-arousal. On the other hand, $11 \%$ of the participants from the sample mentioned that high BI/SW may be also associated with the development of negative self-cognitions. For example, Rose explained:

"Highly inhibited children may develop negative perceptions of self-competence when they compare themselves with their peers. As they grow up, highly inhibited children begin to notice that they don't have the same performance and that they don't feel as relaxed as their peers in social situations. This may interfere in child's self-esteem." 
Consequences for child's family. All groups recognized that high BI/SW may be associated with parental excessive worry and overprotection toward the child, which contribute to reinforce child BI/SW. According to the participants, parental worry and overprotection may be more common among parents who also display high BI/SW.

In contrast, most participants from FG2, 11\% of the participants from FG3 and six percent of the participants from FG1 mentioned that high BI/SW may be associated with parental normalization and misunderstanding. This may be more common among parents who did not display high BI/SW. Participants recognized that parents may not be fully aware of their child's difficulties and often believe that these difficulties will disappear spontaneously as the child grows up, especially if these behaviors essentially manifest themselves at preschool. These parental beliefs were linked to the typical misconceptions of Portuguese preschool teachers toward BI/SW, as explained by Claudia:

"During the preschool years, parents often look for information about their child's behavior with preschool teachers to understand if this behavior is also a problem at preschool. According to my experience, the normalization of high BI/SW often starts at preschool. Highly inhibited children do not manifest disruptive behaviors that interfere negatively in the classroom functioning. Preschool teachers have a high number of children in the classroom, so that highly inhibited children are perceived to have a functional behavior."

Participants explained that these beliefs toward BI/SW may result in parental criticism and excessive pressure toward the child to approach feared social situations and may, ultimately, reinforce child's difficulties.

Six percent of the participants from FG2 and six percent of participants from FG3 mentioned that high BI/SW may be associated with interaction problems with other family members, namely child's siblings and enlarged family. Interaction problems with other family members may influence negatively parents' mood and their perceptions of parenting competence to manage child's difficulties. Six percent of the participants from FG3 also mentioned that high BI/SW may be associated with stress in the couple relationship, especially when one of the parents attribute the causes of child's behavior to the other parent or disagree with the coping strategies that the other parent use to manage their child's difficulties.

\section{Intervention needs related to $\mathrm{BI} / \mathrm{SW}$}

Most participants from FG1, 11\% of the participants from FG2 and 11\% of the participants from FG3 recommended psychoeducation about BI/SW for parents and preschool teachers, based on a developmental and transactional approach. According to them, the first step would be to provide information about the evolutionary origins of $\mathrm{BI} / \mathrm{SW}$, the differences between its normative and nonnormative manifestations, the negative long-term effects of avoidance, the family factors that maintain $\mathrm{BI} / \mathrm{SW}$ across time, and the warning signs that may justify help-seeking. For example, Amanda explained:

"I think that it is important to help parents and preschool teachers to understand what causes BI. The psychoeducation about the anxiety mechanisms, what can maintain or modify them is very important."

Twenty-two percent of the participants from the sample mentioned that the need to modify the dysfunctional beliefs and attitudes (e.g., myths about the origins of the BI/SW and the factors that maintain it, criticism toward child's behavior, self-criticism about parenting and teaching skills) that can negatively influence the behaviors of parents and preschool teachers toward inhibited children.

All groups mentioned that interventions targeted at BI/SW need to be primarily family-focused. Half of the participants of FG1 and 11\% of the participants from FG2 suggested the promotion of emotionregulation skills of children and their parents. According to them, inhibited children and their parents need to learn to manage their negative emotions (especially, anxiety) more effectively before intervening in the modification of child's behavior. For example, Susan explained:

"Emotion-regulation exercises to manage negative emotions (such as, breathing or distraction strategies) are helpful, so that they can become more aware of the situations. Sometimes, it involves very concrete strategies that enhance the focus on the present moment and grounding. Then, we are able to intervene when they are calm and emotionally regulated".

With respect to the modification of child's behavior, half of the participants from FG1 and 11\% of the participants from FG3 mentioned that the gradual exposure to feared situations and the reinforcement 
of social-approach behavior (using labelled praise and encouragement) are important components of the interventions targeted at BI/SW.

Conversely, FG2 highlighted the promotion of parenting skills and the modification of parent-child interactions. In fact, sharing experiences and discussing more effective parenting skills with other parents may minimize intrusive and controlling parenting behaviors that typically maintain BI/SW. Given the advantages of vicarious learning and modelling, participants suggested that the interventions targeted at BI/SW need to include the observation of alternative parenting strategies (using video-based or in-vivo observation activities) and the practice of these skills during parent-child sessions, in a secure and nonjudgmental context. As explained by Iris, these intervention strategies may reduce the focus on child's behavior as a problem, enhance perceived parenting self-efficacy and increase parents' perceived control in the modification of child's behaviors:

"I think that a family-focused intervention is important, because BI is not only a child's problem but also a family problem. This kind of intervention allows us to involve the other members of the family (...) can enhance parents' awareness toward their responsibility in problem-solving (...) and provide them parenting strategies that can help them to manage child's difficulties."

Seventeen percent of the participants from the sample mentioned that couple-focused interventions to ensure that parents respond to the child in a consistent manner and to solve potential conflicts related to the attribution of the causes of child's difficulties.

Seventeen percent of the participants from FG2 and $11 \%$ of the participants from FG3 recommended the supervision of preschool teachers to promote the generalization of the changes in child's behavior to other contexts. According to them, preschool teachers need to learn effective group management strategies that can help them to modify the classroom dynamics and promote the socioemotional skills of inhibited children. For example, Claudia explained:

"Preschool teachers need to become more aware of their role in the classroom (...) and need to be given the opportunity to learn effective group management strategies in the classroom and to understand what is social status, what is a friend, who is a leader and who is not, so that they can manage the group dynamics effectively".

\section{DISCUSSION}

To our knowledge, this is the first study to explore the perceptions of psychologists about BI/SW, their consequences and related intervention needs among Portuguese psychologists. Globally, our findings showed that Portuguese psychologists: (1) acknowledged the main characteristics and consequences of BI/SW, especially in the social domain; (2) perceived that it would be important to provide psychoeducation to parents and preschool teachers and to modify their dysfunctional beliefs about $\mathrm{BI} / \mathrm{SW}$; and (3) in addition to multi-component family-oriented interventions, they suggested that it would be useful to provide supervision to preschool teachers, so that they can promote the social skills of inhibited children in the classroom.

\section{Perceptions of Portuguese psychologists about BI/SW}

In their descriptions of BI/SW, Portuguese psychologists referred the underlying emotions, behaviors and developmental pathways that have been typically described in Rubin's developmental and transactional model (Rubin et al., 2009). In line with laboratory research reports (Kagan et al., 1987), participants recognized that highly inhibited children typically display observable manifestations of anxiety when exposed to new situations and activities, such as the trend to remain in proximity of caregivers or the reluctance to engage in exploration behaviors. However, psychologists in Portugal discussed, more extensively, the observable manifestations of anxiety when exposed to social interactions with unfamiliar adults and peers and, gradually, with familiar peers at preschool. This is consistent with the developmental and transactional framework, which establishes that child's high reactivity to unfamiliar social and non-social stimuli is posited to be an antecedent of SW in familiar social contexts (Fox et al., 2001). More specifically, the descriptions of Portuguese psychologists seem to reflect the conflicted motivations of approach and avoidance toward social interactions that are typically associated with BI/SW (Asendorpf, 1990; Coplan, Prakash, Neil, \& Armer, 2004), due to internalized feelings of social anxiety (Rubin et al., 2018). In fact, participants recognized that highly inhibited children tend to exhibit social avoidance behaviors (e.g., avoiding eye contact, refraining from initiating conversations) and to remove themselves from the peer group through the consistent display of solitary play with peers in the preschool (Rubin et al., 2009). On the other hand, participants also reported that inhibited children often 
exhibit onlooking or freezing behaviors when exposed to social interactions, which may reflect their motivation to approach others refrained by fear-induced social avoidance (Asendorpf, 1990; Coplan et al., 2004).

\section{Perceptions of Portuguese psychologists about the consequences of BI/SW for child's socioemotional adjustment}

In line with a developmental and transactional framework (Rubin et al., 2009), Portuguese psychologists acknowledged that high BI/SW may be associated with a variety of negative socioemotional consequences from early childhood to adolescence.

With respect to the negative socioemotional consequences associated with BI/SW during early childhood, the reflections of the participants are consistent with classical theoretical work that provide support for the idea that children's peer interactions during early childhood serve to promote adaptive emotional, social and socio-cognitive functioning (Rubin, Bowker et al., 2018). In fact, Portuguese psychologists anticipated that inhibited young children can experience similar emotion-regulation difficulties to those that have been described in prior research, that is, low thresholds for the evocation of negative affect (especially, social fear and anxiety) during the exposure to social novelty (Kagan et al. 1987; Rubin et al., 1995; Rubin et al., 2001). Consistent with prior research conducted with Portuguese samples (Coelho, Guedes, Rodrigues, Santos, \& Veríssimo, 2018), our participants also referred that inhibited young children can also display lower levels of emotional knowledge than their non-inhibited peers, especially increased difficulties in expressing and interpreting emotions. This may be due to the fact that the ability to manage negative emotions without becoming extremely upset when exposed to challenging social situations and the ability to identify emotions and recognize their causes typically enable children to engage more easily in play behaviors or social interactions with peers and, ultimately, increase their social standing in the peer group (Sette, Baumgartner, Laghi, \& Coplan, 2016; Smith et al., 2019). On the other hand, Portuguese psychologists also anticipated that withdrawing from social situations and peer interactions can prevent inhibited preschoolers from engaging in developmentally important learning experiences and from developing age-appropriate social and socio-cognitive skills, such as learning about social environments and how to behave within them, interpersonal negotiation and perspective-taking, understanding others' thoughts and emotions and the self in relation to others (Rubin, Bowker et al., 2018). These findings are consistent with prior studies conducted in Portuguese samples, showing that preschool children who exhibit lower levels of social engagement display lower levels of social competence than their peers, when using broadband assessments that include affect expression within social transactions and the ability to modulate it successfully to achieve goals within the social group (Santos, Daniel, Antunes, Coppola, Trudel, \& Vaughn, 2020; Santos, Monteiro, Sousa, Fernandes, Torres, \& Vaughn, 2015; Vaughn et al., 2016). The emphasis of Portuguese psychologists on the idea that emotional abilities are non-dissociable from social competence (Santos et al., 2020) may reflect the salience of sociability and emotional expressiveness in Southern European cultures (Casiglia et al., 1998).

Furthermore, Portuguese psychologists discussed the negative implications of high and stable BI/SW for preschool children's learning experiences. Consistent with prior research (Coplan \& Weeks, 2009; Dobbs et al., 2006; Spere \& Evans, 2009; Spere et al., 2004; Strand et al., 2011), participants anticipated that socially wary preschoolers may be at increased risk of displaying lower levels of linguistic and pre-academic skills than their non-inhibited peers. In fact, the low levels of involvement of inhibited children in verbal interactions and exploration behaviors at preschool can limit the amplitude and quality of their learning experiences and their opportunities for mastering pre-academic tasks (Kalutskaya et al., 2015). Due to their increased levels of social anxiety and self-consciousness, our participants also acknowledged that performance activities requiring the demonstration of linguistic and pre-academic skills in front of preschool teachers and/or peers may be particularly challenging for socially wary preschoolers (Coplan \& Evans, 2009).

With respect to the long-term consequences of high and stable BI/SW during early childhood, the descriptions of psychologists in Portugal are also consistent with Rubin's developmental and transactional model (Rubin et al., 2009). Due to low emotional, social and socio-cognitive competencies, our participants acknowledge that children who continue to display socially wary behaviors over time are more likely to internalize negative thoughts and feelings about the self (i.e., negative comparisons with peers about their social and performance skills), to experience later difficulties in establishing appropriate social interactions and, ultimately, peer exclusion and victimization (Correia et al., 2014; Rubin, Barstead et al., 2018). Given the salience of sociability in Southern European cultures (Casiglia et al., 1998), BI/SW may be viewed as especially deviant from social norms and expectations for social relationships and may evoke particularly negative peer reactions (Rubin, Bowker et al., 2018; Rubin et al., 
2009). This may explain why the descriptions of Portuguese psychologists emphasized the long-term peer difficulties associated with high and stable BI/SW. Consistent with prior research (Kalutskaya et al., 2015), our participants anticipated that the lower behavioral engagement of socially wary children in classroom activities and their negative self-perceptions can have negative implications in long-term academic outcomes. In particular, the descriptions of psychologists suggest that the long-term academic consequences associated with high BI/SW may be linked to teachers' attitudes and responses toward these social behaviors. As found in prior research (Kalutskaya et al., 2015), our participants acknowledge that withdrawn children tend to go unnoticed by teachers and to receive fewer teacher-initiated interactions, because they usually remain quiet during the classroom activities. This may have negative implications for the early identification of learning difficulties among withdrawn children.

\section{Perceptions of Portuguese psychologists about the consequences of BI/SW for child's family}

With respect to consequences for child's family, the perspectives of psychologists in Portugal were in line with a developmental and transactional theoretical approach (Rubin et al., 2009), showing that BI/SW often evoke anxious and overprotective parenting reactions that refrain children from engaging in developmentally important experiences and, thus, contribute to its continuity over time (Hane et al., 2008; Lewis-Morrarty et al., 2012). In contrast, the reflections of the second focus group support the idea that parents are more prone to believe that anxiety-related problems are normative and will disappear spontaneously as the child grows up (Carpenter et al., 2018; Mian, 2014; Reardon et al., 2018). The higher representation of developmental psychologists, who work in normative school contexts, may explain why this topic was more extensively discussed by the second focus group.

In line with the theoretical help-seeking models (Cauce et al., 2002; Godoy \& Carter, 2013; Srebnik et al., 1996), our findings suggest that the appraisals of professionals toward BI/SW can interfere negatively with parental problem recognition. Contrary to the recent findings that have emphasized that US teachers are increasingly concerned about the consequences of BI/SW (Coplan et al., 2015; Coplan et al., 2011), Portuguese psychologists referred that preschool teachers tend to normalize these social behaviors and even emphasize its advantages for the classroom functioning. The appraisals of Portuguese preschool teachers toward BI/SW may be associated with the high ratio of preschool children per classroom and per teacher in the country (Organisation for Economic Co-operation and Development [OECD], 2016a). However, all groups acknowledged that these appraisals can be an additional barrier to parental problem recognition. This may be especially relevant in Portugal, which is one of the OECD countries, where young children spend more hours in early childhood care and education services, due to the high rate of full-time labor market participation among mothers of children under five (OECD, 2016b).

Furthermore, Portuguese psychologists recognized that the dysfunctional beliefs of parents and teachers toward BI/SW may be associated with reduced warmth and sensitivity, which can ultimately, contribute to their continuity over time. This is consistent with prior research that found that inhibited children may be placed on a more negative developmental trajectory, when parents respond to them with a lack of warmth and sensitivity (Hane et al., 2008; Lewis-Morrarty et al., 2012) or when the closeness of the teacher-child relationship is low (Arbeau, Coplan, \& Weeks, 2010).

According to the participants, BI/SW can also affect negatively the quality of the relationships with other members of the nuclear (e.g., marital partner, siblings) and extended family (e.g., grandparents). These findings seem to be consistent with the idea that family is an important source of emotional and advice-giving support in times of stress in family-oriented cultures (Wall \& Gouveia, 2014). In line with this perspective, Portuguese psychologists suggested that family conflicts due to child's BI/SW may be associated with parental depression and low parenting self-confidence.

\section{Perceptions of Portuguese psychologists about the intervention needs related to BI/SW}

With respect to the intervention needs related to $\mathrm{BI} / \mathrm{SW}$, psychologists in Portugal recommended psychoeducation about BI/SW for parents and preschool teachers to enhance the recognition of child's $\mathrm{BI} / \mathrm{SW}$ and reframe their perceptions about these social behaviors, in a more realistic way. More specifically, participants suggested the focus on contents (i.e., etiology and development of anxiety, contributions of family factors for child's behavior, avoidance and negative reinforcement processes) that are part of the parent psychoeducational sessions in the Cool Little Kids (Rapee \& Jacobs, 2002) and in the Turtle Program (Chronis-Tuscano et al., 2015). Like in the Cool Little Kids (Rapee \& Jacobs, 2002), participants recommended the cognitive restructuring of dysfunctional beliefs that lead to overprotective and/or insensitive responses toward child's inhibited behaviors. In line with the more recent advances in this intervention field (Chronis-Tuscano et al., 2018), Portuguese psychologists recommended multicomponent family interventions targeted at parents (individually and as a couple) and at young children.. Specifically, participants suggested similar psychoeducational contents to those of the Cool Little Kids 
(Rapee \& Jacobs, 2002) and the Turtle Program (Chronis-Tuscano et al., 2015), such as effective emotionregulation skills, alternative management techniques to overcome overprotective and anxiogenic parenting behaviors, gradual exposure to feared social situations, and reinforcement of social-approach behaviors. However, the reflections of psychologists in Portugal are also consistent with the findings of the meta-analysis of Kaminski, Valle, Fillen and Boyle (2008). In fact, participants emphasized that the observation and practice of parenting skills with children would be more effective for Portuguese families than purely psychoeducational approaches. Furthermore, participants suggested the introduction of a parallel child component with similar characteristics to those of the Turtle Program (Chronis-Tuscano et al., 2015) that can promote effective emotion-regulation and social skills to prevent the maintenance of $\mathrm{BI} / \mathrm{SW}$ over time and the risk of developing later negative socioemotional consequences.

Due to their important role in the lives of Portuguese young children (OECD, 2016b), psychologists recommended the development of specific intervention components targeted at preschool teachers. Involving preschool teachers in interventions programs targeted at BI/SW is essential. In fact, preschool teachers are thought to be both caregivers and educators, who provide children with warmth and nurturance but also with important learning experiences that can influence children's later emotional, social and academic outcomes (Coplan et al., 2015). Consistent with US research on the perspectives of teachers about BI/SW related intervention needs (Bosaki et al., 2011), participants suggested that Portuguese preschool teachers need to learn and practice the introduction of alternative educational strategies that can model and encourage the verbal communication and gradual social approachbehaviors of inhibited children with their peers in the classroom. This is in line with the scaffold-andstretch approach targeted at shy low-income primary-grade children in the teacher component of the comprehensive temperament-based INSIGHTS Program (O'Connor, Cappella, McCormick, \& McClowry, 2014). In this approach, teachers are taught to reorganize classroom challenging activities in more manageable steps for shy children and to acknowledge children's efforts in engaging in progressively more complex steps (Kalutskaya et al., 2015; O'Connor et al., 2014). This scaffold-and-stretch approach follows the principles of graduated exposure techniques that are part of the Cool Little Kids (Rapee \& Jacobs, 2002) and the parent component of the Turtle Program (Chronis-Tuscano et al., 2015).

\section{Limitations and implications for future studies}

To our knowledge, this is the first study that explored the perceptions of Portuguese psychologists toward BI/SW and their related intervention needs. Given its exploratory nature, the qualitative approach based on focus groups allowed us to gain a deeper understanding of practitioners' views. However, some limitations must be acknowledged. The sample consisted of a majority of females. The group format and the familiarity of the moderator with some participants and between some participants may have contributed to the inhibition or desirability of some responses. Given the objectives of the study, the thematic analysis followed a descriptive approach that considered the frequency, extensiveness, intensity, specificity, internal consistency and perception of importance (Krueger \& Casey, 2014). However, we did not conduct an analysis of the group interactions that are sometimes valued in focus group data analysis. A respondent validation strategy was used, but we did not make a triangulation with other methods (e.g., self-reports) to extend our understanding of the perspectives of Portuguese psychologists.

Future studies need to overcome these methodological limitations and explore the perceptions of parents and preschool teachers about BI/SW to identify potential gaps in the recognition and effective management of these early risk social behaviors. This can inform tailoring needed for the development of new multimodal evidence-based intervention programs targeted at BI/SW that include the multiple educative agents, who may influence the stability of these early risk social behaviors over time and, ultimately, children's later emotional, social and academic outcomes.

\section{REFERENCES}

Arbeau, K. A., Coplan, R. J., \& Weeks, M. (2010). Shyness, teacher-child relationships, and socioemotional adjustment in grade 1. International Journal of Behavioral Development, 34, 259-269. doi;10.1177/0165025409350959

Asendorpf, J. (1990). Beyond social withdrawal: Shyness, unsociability, and peer avoidance. Human Development, 33, 250-259. https://doi.org/10.1159/000276522

Bandelow, B., \& Michaelis, S. (2015). Epidemiology of anxiety disorders in the 21rst century. Dialogues in Clinical Neuroscience, 17, 327-335.

Barstead, M (in press). Psychosocial correlates of social withdrawal and its many variants: A quantitative synthesis of research spanning four decades. https://doi.org/10.13140/RG.2.2.25266.09925 
Bayer, J., Baetson, R., Bretherton, L., Hiscock, H., Wake, M., Gilbertson, T., Mihapoulous, C., ... \& Rapee, R. M. (2017). Translational delivery of Cool Little Kids to prevent child internalizing problems: Randomized controlled trial. Australian \& New Zealand Journal of Psychiatry, 52, 181-191. https://doi.org/10.1177/0004867417726582

Bosacki, S., Coplan, R. J., Rose-Krasnor, L., \& Hughes, K. (2011). Elementary teachers' reflections of shy children in the classroom. Alberta Journal of Educational Psychology, 57(3), 273-287.

Braun, V., \& Clarke, V. (2006). Using thematic analysis in psychology. Qualitative Research in Psychology, 3, 77-101. https://doi.org/10.1191/1478088706qp063oa

Bronfenbrenner, U., \& Morris, P. A. (2006). The bioecological model of human development. In R. M. Lerner \& W. Damon (Eds.), Handbook of child psychology: Theoretical models of human development (pp. 793-828). John Wiley \& Sons Inc.

Caldas-Almeida, J., \& Xavier, M. (2013). Epidemiological national study about mental health: First report. Lisbon: Faculdade de Ciências Médicas da Universidade de Lisboa.

Carpenter, A. L., Pincus, D. B., Perrin, E., Bair-Merrit, M. H., \& Mian, N. D. (2018). Early identification of anxiety disorders: The role of the pediatrician in primary care. Children's Health Care, 47, 34-50. https://doi.org/10.1080/02739615.2016.1275642

Casiglia, A. C., LoCoco, A., \& Zappulla, C. (1998). Aspects of social reputation and peer relationships in Italian children: A cross-cultural perspective. Developmental Psychology, 34, 723-730. https://doi.org/10.1037/0012-1649.34.4.723

Cauce, A. M., Dominech-Rodriguéz, M., Paradise, M., Cochran, B. N., Shea, J. M., Srebnik, D., \& Baydar, N. (2002). Cultural and contextual influences in mental health help seeking: A focus on ethnic minority youth. Journal of Consulting and Clinical Psychology, 70, 44-55. https://doi.org/10.1037/0022-006X.70.1.44

Chronis-Tuscano, A., Danko, C., Rubin, K. H., Coplan, R. J., \& Novick, D. (2018). Future directions for research on early intervention for young children at risk of social anxiety. Journal of Clinical Child and Adolescent Psychology, 47(4), 655-667.. https://doi.org/10.1080/15374416.2018.1426006

Chronis-Tuscano, A., Degnan, K. A., Pine, D. S., Perez-Edgar, K., Henderson, H. A., Diaz, Y., Raggi, V. L., \& Fox, N. A. (2009). Stable early maternal report of behavioral inhibition predicts lifetime social anxiety disorder in adolescence. Journal of the American Academy of Child \& Adolescent Psychiatry, 48, 928935. https://doi.org/10.1097/CHI.0b013e3181ae09d

Chronis-Tuscano, A., Rubin, K. H., O’Brien, K. A., Coplan, R. J., Thomas, R., Dougherty, L. R. ... \& Wimsatt, M. (2015). Preliminary evaluation of a multi-modal early intervention for inhibited preschoolers. Journal of Consulting and Clinical Psychology, 83, 534-540. https://doi.org/10.1037/a0039043

Coelho, L., Guedes, M., Rodrigues, E. D., Santos, A. J., \& Veríssimo, M. (2018). Perfis de brincadeira e conhecimento emocional em crianças de idade pré-escolar [Play profiles and emotional knowledge in preschool children]. Análise Psicológica, 26, 87-100. https://doi.org/10.14417/ap.1357

Coplan, R. J., \& Arbeau, K. A. (2008). The stresses of a brave new world: Shyness and school adjustment in kindergarten. Journal of Research in Childhood Education, 22, 377-389. https://doi.org/10.1080/02568540809594634

Coplan, R. J., \& Evans, M. A. (2009). At loss for words? Introduction to the special issue on shyness and language in childhood. Infant and Child Development, 18, 211-215. https://doi.org/10.1002/icd.620

Coplan, R. J., \& Weeks, M. (2009). Shy and soft-spoken: Shyness, pragmatic language, and socio-emotional adjustment in early childhood.Infant and Child Development, 18(3), 238254. https://doi.org/10.1002/icd.622

Coplan, R. J., Bullock, A., Archbell, K. A., \& Bosacki, S. (2015). Preschool teachers' attitudes, beliefs, and emotional reactions to young children's peer group behaviors. Early Childhood Research Quarterly, 30(Part A), 117-127. https://doi.org/10.1016/j.ecresq.2014.09.005

Coplan, R. J., Hughes, K., Bosacki, S., \& Rose-Krasnor, L. (2011). Is silence golden? Elementary school teachers' strategies and beliefs regarding hypothetical shy/quiet and exuberant/talkative children. Journal of Educational Psychology, 103, 939-951. https://doi.org/10.1037/a0024551

Coplan, R. J., Prakash, K., O’Neil, K., \& Armer M. (2004). Do you "want" to play? Distinguishing between conflicted-shyness and social disinterest in early childhood. Developmental Psychology, 40, 244258. https://doi.org/10.1037/0012-1649.40.2.244

Coplan, R. J., Schneider, B. H., Matheson, A., \& Graham, A. (2010). Play skills for shy children: Development of a social facilitated play early intervention program for extremely inhibited preschoolers. Infant Child and Development, 19, 223-237. https://doi.org/10.1002/icd.668 
Correia, J., Santos, A. J., Freitas, M., Ribeiro, O., \& Rubin, K. H. (2014). As relações entre pares de adolescentes socialmente retraídos [The peer relationships of socially withdrawn adolescents]. Análise Psicológica, 32, 467-479. https://doi.org/10.14417/ap.870

Danko, C.M., O'Brien, K.A., Rubin, K.H., \& Chronis-Tuscano, A. (2018). The Turtle Program: PCIT for young children displaying behavioral inhibition. In L.N. Niec (Ed.), Handbook of Parent-Child Interaction Therapy: Innovations and applications for research and practice (pp.85-98). Springer.

Dobbs, J., Doctoroff, G. L., Fisher, P. H., \& Arnold, D. H. (2006). The association between preschool children's socio-emotional functioning and their mathematical skills. Journal of Applied Developmental Psychology, 27(2), 97-108. https://doi.org/10.1016/j.appdev.2005.12.008

Eyberg, S. M., Nelson, M. M., \& Boggs, S. R. (2008). Evidence-based psychosocial treatments for children and adolescents with disruptive behavior. Journal of Clinical Child and Adolescent Psychology, 37, 215-237. https://doi.org/10.1080/15374410701820117

Fox, N. A., Henderson, H. A., Rubin, K. H., Calkins, S. D., \& Schmidt, L. A. (2001). Continuity and discontinuity of behavioral inhibition and exuberance: Psychophysiological and behavioral influences across the first four years of life. Child Development, 72, 1-21. https://doi.org/10.1111/1467-8624.00262

Fox, N., Henderson, H. A., Marshall, P. J., Nichols, K. E., \& Ghera, M. M. (2005). Behavioral inhibition: Linking biology and behavior within a developmental framework. Annual Review of Psychology, 56, 235-262. https://doi.org/10.1146/annurev.psych.55.090902.141532

Godoy, L., \& Carter, A. S. (2013). Identifying and addressing mental health risks and problems in primary care pediatric settings: A model to promote developmental and cultural competence. American Journal of Orthopsychiatry, 83, 73-88. https://doi.org/10.1111/ajop.12005

Guedes, M., Coelho, L., Santos, A. J., Veríssimo, M., Rubin, K. H., Danko, C., \& Chronis-Tuscano, A. (2019). Perceptions of Portuguese psychologists about the acceptability of a parent intervention targeted at inhibited preschoolers. Evidence-Based Practice in Child and Adolescent Mental Health, 4(1), 1-17. https://doi.org/10.1080/23794925.2018.1555443

Hane, A. A., Cheah, C., Rubin, K. H., \& Fox, N. A. (2008). The role of maternal behavior in the relation between shyness and social reticence in early childhood and social withdrawal in middle childhood. Social Development, 17, 795-811. https://doi.org/10.1111/j.1467-9507.2008.00481

Hirschfeld-Becker, D. R., \& Biederman, J. (2002). Rationale and principles for early intervention with young children at risk for anxiety disorders. Clinical Child and Family Psychology Review, 5, 161172. https://doi.org/10.1023/A:1019687531040

Huberman, A. M., \& Miles, M. B. (1994). Data management and analysis method. In N. Denzin \& Y. Lincoln (Eds.), Handbook of qualitative research (pp. 428-444). Sage Publications.

Kagan, J., Reznick, J. S., \& Snidman, N. (1987). The physiology and psychology of behavioral inhibition in children. Child Development, 58, 1459-1473.

Kalutskaya, I., Archbell, K. A., Rudasill, K. M., \& Coplan, R. J. (2015). Shy children in the classroom: From research to educational practice. Translational Issues in Psychological Science, 1.2., 149-157. https://doi.org/10.1037/tps0000024

Kaminski, J. W., Valle, L. A., Filene, J. H., \& Boyle, C. L. (2008). A meta-analytic review of components associated with parent training program effectiveness. Journal of Abnormal Child Psychology, 36, 567-589. https://doi.org/10.1007/s10802-007-9201-9

Krueger, R. A., \& Casey, M. A. (2014). Focus groups: A practical guide for applied research (5 ${ }^{\text {th }}$ ed.). Sage.

Lewis-Morrarty, E., Degnan, K. A., Chronis-Tuscano, A., Rubin, K. H., Cheah, C. S. L., Pine, D. S., Henderson, H. A., \& Fox, N. A. (2012). Maternal over-control moderates the association between early childhood behavioral inhibition and adolescent social anxiety symptoms. Journal of Abnormal Child Psychology, 40, 1363-1373. https://doi.org/10.1007/s10802-012-9663-2

McCabe, K. M., \& Yeh, M. (2005). The GANA Program: A tailoring approach to adapting parent-child interaction therapy for Mexican Americans. Education and Treatment of Children, 28, 111-129.

Mian, N. D. (2014). Little children with big worries: Addressing the needs of young, anxious children and the problem of parent engagement. Clinical Child and Family Psychology Review, 17, 85-96. https://doi.org/10.1007/s10567-013-0152-0

O’Brien, D., Harvey, K., Howse, J., Reardon, T., \& Creswell, C. (2016). Barriers to managing child and adolescent mental health problems: A systematic review of primary care practitioners' perceptions. British Journal of General Practice, 66(651), e693-707. https://doi.org/10.3399/bjgp16X687061

O’Brien, D., Harvey, K., Young, B., Reardon, T., \& Creswell, C. (2017). GP's experiences of children with anxiety disorders in primary care: A qualitative study. British Journal of General Practice, 67(665), e888-e898 https://doi.org/10.3399/bjgp17X693473 
O'Connor, E. E., Cappella, E., McCormick, M. P., \& McClowry, S. G. (2014). Enhancing the academic development of shy children: A test of the efficacy of INSIGHTS. School Psychology Review, 43, 239259.

Organisation for Economic Co-operation and Development (2016a). Education at a glance. Author.

Organisation for Economic Co-operation and Development (2016b). Society at a glance: OECD social indicators. Author.

Pincus, D. B., Eyberg, S. M., \& Choate, M. L. (2005). Adapting Parent-Child Interaction Therapy for young children with separation anxiety disorders. Education and Treatment of Children, 28, 163-181.

Rapee, R. M., \& Jacobs, D. (2002). The reduction of temperamental risk for anxiety in withdrawn preschoolers: A pilot study. Behavioural and Cognitive Psychotherapy, 30, 211-215. https://doi.org/10.1017/S1352465802002084

Rapee, R. M., Kennedy, S., Ingram, M., Edwards, S., \& Sweeney, L. (2005). Prevention and early intervention of anxiety disorders in inhibited preschool children. Journal of Consulting and Clinical Psychology, 73, 488-497. https://doi.org/10.1037/0022-006X.73.3.488

Reardon, T., Harvey, K., Young, B., O’ Brien, D., \& Creswell, C. (2018). Barriers and facilitators to parents seeking and accessing professional support for anxiety disorders in children: Qualitative interview study. European Child and Adolescent Psychiatry, 27, 1023-1031. https://doi.org/10.1007/s00787018-1107-2

Rubin, K. H., Bowker, J. C., Barstead, M. G., \& Coplan, R. J. (2018). Avoiding and withdrawing from the peer group. In W. M. Bukowski, B. Laursen, \& K. H. Rubin (Eds.), Handbook of peer interactions, relationships and groups (2nd ed.) (pp. 322-346). The Guilford Press.

Rubin, K. H., Cheah, C., \& Fox, N. (2001). Emotion regulation, parenting and display of social reticence in preschoolers. Early Education and Development, 12, 97-115. https://doi.org/10.1207/s15566935eed1201_6

Rubin, K. H., Coplan, R. J., \& Bowker, J. C. (2009). Social withdrawal in childhood. Annual Review of Psychology, 60, 141-171. https://doi.org/10.1146/annurev.psych.60.110707.163642

Rubin, K. H., Coplan, R. J., Fox, N. A., \& Calkins, S. D. (1995). Emotionality, emotion regulation, and preschoolers' social adaptation. Development and Psychopathology, 7(1), 4962. https://doi.org/10.1017/S0954579400006337

Rubin, K. H., Hemphill, S. A., Chen, X., Hastings, P., Sanson, A., lo Coco, A., ... \& Doh, H. S. (2006). Parenting beliefs and behaviors: Initial findings from the International Consortium for the Study of Social and Emotional Development (ICSSED). In K. H. Rubin \& O. B. Chung (Eds.), Parenting beliefs, behaviors, and parent-child relationships: A cross-cultural perspective (pp. 81-103). Psychology Press.

Rubin, K.H., Barstead, M.G., Smith, K.A., \& Bowker, J.C. (2018). Peer relations and the behaviorally inhibited child. In K. Perez-Edgar \& N.A. Fox (Eds.), Behavioral inhibition during childhood and adolescence (pp. 157-184). Springer.

Santos, A. J., Daniel, J., Antunes, M., Coppola. G., Trudel, M., \& Vaughn, B. (2020). Change in preschool children's children social engagement positively predicts changes in social competence: A threeyear longitudinal study of Portuguese children. Social Development, 29(2), 544-563. https://doi.org/10.1111/sode.12411

Santos, A. J., Monteiro, L., Sousa, T., Fernandes, C., Torres, N., \& Vaughn, B. (2015). Low social engagement: Implications for children psychosocial adjustment in the preschool context. Psicologia: Reflexão $e$ Crítica, 28, 186-193. https://doi.org/10.1590/1678-7153.201528120.

Sette, S., Baumgartner, E., Laghi, F., \& Coplan, R. J. (2016). The role of emotion knowledge in the links between shyness and children's socio-emotional functioning at preschool. British Journal of Developmental Psychology, 34, 471-488. https://doi.org/10.1111/bjdp

Smith, K. A., Hastings, P. D., Henderson, H. A., \& Rubin, K. H. (2019). Multidimensional emotion regulation moderates the relation between behavioral inhibition at age 2 and social reticence with unfamiliar peers at age 4. Journal of Abnormal Clinical Psychology. https://doi.org/10.1007/s10802-01800509-y

Spere, K. A., Schmidt, L. A., Theall, L., \& Martin-Chang, S. L. (2004). Expressive and receptive language skills of temperamentally shy preschoolers. Infant and Child Development, 13(2), 123-133. https://doi.org/10.1002/icd.345

Spere, K., \& Evans, M. A. (2009). Shyness as a continuous dimension and emergent literacy in young children: Is there a relation? Infant and Child Development, 18(3), 216237. https://doi.org/10.1002/icd.621

Srebnik, D., Cauce, A. M., \& Baydar, N. (1996). Help-seeking pathways for children and adolescents. Journal of Behavioral and Emotional Disorders, 4, 210-220. https://doi.org/10.1177/106342669600400402 
Strand, P. S., Pula, K., Parks, C. D., \& Cerna, S. (2011). Shyness-anxiousness and receptive language skills development in Spanish- and English-speaking preschoolers. Journal of Applied Developmental Psychology, 32, 363-366. https://doi.org/10.1016/j.appdev.2011.06.002

Vaughn, B., Santos, A. J., Monteiro, L., Shin, N., Daniel, J. R., Krzysik, L., \& Pinto, A. (2016). Social engagement and adaptive functioning during early childhood: Identifying and distinguishing among subgroups differing with regard to social engagement. Developmental Psychology, 52, 4221434. https://doi.org/10.1037/dev0000142

Wall, K., \& Gouveia, R. (2014). Changing meanings of family in personal relationships. Current Sociology, 62, 352-373. https://doi.org/10.1177/0011392113518779

Historial do artigo

Recebido $\quad 12 / 2018$

Aceite $\quad 01 / 2020$

Publicado $\quad 08 / 2020$ 